SCHOLARS: Journal of Arts \& Humanities Print ISSN: 2773-7829; e-ISSN: 2773-7837

eJournal Site: www.cdetu.edu.np/ejournal/

- Peer-Reviewed, Open Access Journal

- Indexed in NepJOL; Star-Ranked in JPPS

Central Department of English

- Permanently Archived in Portico

Tribhuvan University

Kirtipur, Nepal

URL: www.cdetu.edu.np

Original Research Article

DOI: https://doi.org/10.3126/sjah.v4i1.43051

\title{
Visual Images and Interpretations: A Semiotic Analysis of Textbook Covers
}

\author{
Pragya Paneru \\ Nepal Commerce Campus, Kathmandu, Nepal \\ Corresponding Author: Pragya Paneru, Email: pragya.miracle@gmail.com
}

\begin{abstract}
This article presents a comparative visual interpretation of the cover images of the selected textbooks. A social semiotic approach was used to analyse various compositional and thematic differences among two sets of textbook covers. The compositional interpretation was applied to explore the differences and similarities in an image composition and discourse analysis was used to explore their implied social discourses. The findings show some significant shift as well as continuum in the image composition and underlined social discourses. For example, the newly published textbooks focus on settings, character details and character connection, and use various colours in contrast to the old textbook covers. More activities promoting gender equality were found in the new textbook covers than in the old textbook covers. Overall, the new textbooks propose positive changes in their cover image composition in quality and gender discourses. However, the images only feature-specific religious symbols, regional culture and geography rather than multicultural, multiregional and multi-religious context of Nepali society. It seems that minority religion, ethnicity and regional variations that are found in Nepal are missing in the cover images across the curriculum. This article is expected to address the gap seen in the Nepali school educational research and helpful to provide insights that the cover images used in the textbooks are important and powerful meaning makers.
\end{abstract}

Keywords: Textbooks, social semiotics, discourse analysis, gender, culture

\section{Introduction}

The images are significant as they represent culture and reproduce existing social values and beliefs; they also critique the existing values (Duncum 16). They are representative and political as they interpret the world offering specific viewpoint (Rose 2). Their representation in the children's books can reinforce potentiality of multiple meanings such as they can reinforce certain ideology, decontextualise the actual event and promote racial attitude (Kim and Short 245). Moreover, the images can also communicate the sentiment of the specific group, their

Article History:

Submitted 10 November 2021

Revised 2 January 2022

Accepted 26 January 2022

Copyright Information:

Copyright 2022 (c) The Author(s). The publisher may reuse published articles with prior permission of the concerned author(s). The work is licensed under a Creative Commons Attibution 4.0 International License (CC BY 4.0).

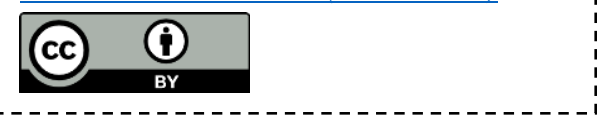

Volume 4, No. 1, February 2022 [pp. 29-43] 
challenges and their dignity like that of the Latinex migrant people (Schall et al. 59). Therefore, in educational materials, the selection of the images puts one into a grave responsibility as images might privilege some group over others impacting their performances and reinforcing inequality (Bates 257). The meanings communicated by the images can also be connotative, referring to specific cultures and symbols (Hoffman 77) and making them difficult to discern for an individual from other cultural contexts. These potentialities make the images important as they can be used to enhance meanings, provide additional information and trigger the readers' experience and understanding (Kim and Short 6).

The images are also powerful pedagogy (Duncum 1). In education, they play a major role as they are used in classrooms during teaching and learning activities. Especially the teaching materials used for the young students are extensively loaded with the images than language. Thus, the textbook images are one of the significant resources throughout the world for an educational purpose. This article contends that images in an education context are vital as they contribute to shape the understandings of the individuals who are directly and indirectly involved in those sites.

Emerging scholarships in visual analysis on the textbook images critically analyse the way various social issues are represented in the children's books. However, none of these studies represent the Nepali contexts. Thus, this article attempts to address this gap by analysing two sets of grade one textbooks covers belonging to the past and present curriculum. The main objective of this article is to investigate a compositional shift and social issues as seen on the cover images across the curriculum of grade one. In doing so, this article exhumes the way general Nepali culture, gender and other social aspects are represented in a total of nine textbook cover images. All the textbook cover images used in this article are extracted from the grade one compulsory textbooks published by the Curriculum Development Centre (CDC). Since the images in the children's book represents popular social discourses and can potentially shape the attitudes of the individuals (Kim and Short 262), this study of textbook cover images is expected to promote critical awareness among the concerned authorities while choosing images for school textbooks.

\section{Literature Review}

There are various studies on the images of the picture books and their meaning making. However, studies exploring both the language and images are more than the studies solely concerning about the images in the picture books or textbooks. Most of these studies on the images are concerned about the representational issues such as gender, sexuality, nationality and culture, masculinity, dominant social discourses, depiction of the father character and so on. These studies are concerned about how the representation in the picture books are biased that promote one type over another, or how it remains inclusive to the minorities. Though based on the visual prompts in the Australian national assessment over a period, Bates' study claims that there are changes in the types of images; however, these images have a potential impact of the privileging group over the other, promoting social stratification (257).

Other studies concerning the images in the children's books are based on the children's response to the images. Among these studies, some studies talk about the significance of the images in extending the children's knowledge about the world as they relate the images to the objects and the objects to the images (Ganea, Pickard and DeLoache 46). Some of them are regarding the effects of the gender stereotypic and counter-stereotypic images on the students and claim that there are negative impacts of the stereotypes on the girls' performance (Good, Woodzicka and Wingfield 132). 
Likewise, some studies are concerned about how the children understand the multimodal texts (Callow 5; Callow 115). They claim that the children make meanings of the images based on their previous experiences, knowledge, written clues and intertextual references (Crawford and Hade 66). The images in the picture books trigger multiple interpretations and understanding of the children, which are further influenced by their cultural and familial backgrounds (Hoel 673). Other studies are concerned about understanding the students' semiotic awareness (Callow 115; Unsworth and Macken-Horarik 56).

There are also studies regarding the teachers' roles in teaching the text contents to avoid possible generalisations and stereotypes. Some of these studies focus on the teachers' awareness about the generalisations (Gouvias and Alexopoulos 642). They claim that the meaning alone cannot be determined by the text but also it is influenced by how these teachers approach it differently and how it is impossible to assume (Sunderland 251). Some are prescriptive on how these teachers should deal with the multimodal texts (Reyes-Torres and Raga 94). Some regard it as the challenges for the teachers to approach the multimodal texts (Ryan, Scott and Walsh 477).

Even though above-mentioned studies were done around the world in the children's books, Nepal lags behind in such type of studies so far. Thus, this article attempts to add in the scholarships in exploring how Nepali culture, gender and other social aspects are represented in the textbook cover images. In addition, it brings forward the compositional shifts in the cover images and their potential impacts on the children. In doing so, this article particularly explores the cover images of all the compulsory textbooks from both the old and new curriculum.

\section{Theoretical Framework}

This article uses the social semiotic theory to reflect on how meaning is communicated in the images. The social semioticians agree that the images are semiotic resources that enable and evoke meanings at three levels: representational, interactional and compositional (Kress and Van Leeuwen 42; Bates 265; Painter 25). Here, the representational meaning making is related to the representation of the type of people, setting and activities in the images. The interactional meaning making is related to the way an image communicates relationships and emotions to the audiences or in-between the represented characters. The compositional meaning making is how an image is composed and what effects are produced because of the placement of various contents in specific spaces in the image area. All three levels of meaning making works to produce the overall meaning of the images and these meanings are influenced by the social context, the context of image readers and the context of image makers (Bates 271; Kress and van Leeuwen 2; Rose 20).

This article uses Gillian Rose's idea of 'compositional interpretation' (56) that is combined with her visual discourse analysis I (187). Both methods consider an image as the focal point of analysis. The compositional interpretation regards the image composition as enabling representations and interactions. According to Rose, it is the compositional aspect that allows representations and interactions in the images because the image composition determines the image contents and their positionality in the image areas, contributing to the representation and interaction. This method looks at the image itself and its technological modality rather than the social (61). Since solely the compositional interpretation is insufficient to address the social contextual aspects of the image, it is combined with Rose's visual discourse analysis I (190). Though her compositional interpretation can be extended in the analysis of the computer games and films, this article uses the aspects that are applicable to only still images. 


\section{Visual Images and Interpretations: A Semiotic Analysis of Textbook Covers 32}

According to Rose, visuality is also a discourse because it makes certain things visible and invisible (188). In doing so, it invests power upon the one than the other. The meaning of images does not only depend just on the image itself, but also it depends on the other images and text suggesting intertextuality (187). Thus, Rose suggests discourse analysis as a method of analysing images, their social context and power/knowledge axis. She divides visual discourse analysis into two parts: discourse analysis I and discourse analysis II (189-190). Her first type of discourse analysis is concerned basically with the types of discourses provoked by the images and its relation to power and knowledge whereas her second type is more concerned with the institutional practices of such discourses. This article uses her first type of discourse analysis to explore the general Nepali culture and other social issues in the textbook cover images. By using this method, this article explores the types of discourses suggested by the images regarding the general culture and other social discourses in terms of the image composition. Her discourse analysis is influenced by Foucault's idea of discourse who regards discourse as statements structuring the readers' thoughts and practices (186). Rose supports Foucault's idea that discourse is powerful because when situated in the powerful institution it can produce the regime of truth and social values that changes across time but when in practice, it directs everyday lives of human in that society (Foucault, Power/ Knowledge 131; Rose 190). The power of discourse lies in its productivity and creativity as it produces and sustains both power and knowledge that ultimately have material effects (Foucault 191). Thus, using discourse analysis as a method focuses on the power axis prevalent within any given text and its knowledge production, creating social effects.

\section{Image Content}

According to Rose, the image contents can be an initial point of exploring images (63). According to her, they refer to the elements that are present in the image site. They may include the characters, setting and activities shown in the images. They potentially suggest exclusion/inclusion, visibility/invisibility, majority/minority, active/passive and power positions with possible impacts on the audiences. All these aspects are dealt in this topic.

\section{Colour}

The use of colour is one of the multifunctional entities as it represents things and objects, interacts emotions, and composes images. Colours have potential effects on the audience through its hue, saturation and value (Rose 65). Here, the hues mean various shades of colour, saturation refers to the purity of a colour in the spectrum and values mean the lightness and darkness of the colour. In the analysis part of this article, only the colours used in the images are discussed. Colours can also suggest distance, moods, emotions, etc.

\section{Spatial Organisation}

The spatial organisation of the images refers to the potential meaning evoked by various placements of different image components in the image space (Rose 66). These spatial positioning of various elements within the image space suggest connection/ disconnection through vectors (lines that are formed by the eye lines and gestures), and distance (distance between the characters in the image and shot distance), rhythm (static or dynamic aspect of image contents), perspectives (external or internal), point of view (the view provided to the audience) and focalization (guided view or unguided view). According to Rose, the spatial organisation of any image has potential impacts upon the 
spectators and produces certain relation between the image and the audience (66). Other spatial organisations include framing, focus, angle and shot distance.

This study examines connection/disconnection, distance, point of view and focalisation to show the major differences and similarities between the images across the curriculum.

\section{Expressive Content}

The expressive content is another important aspect of looking at the images. By expressive content, Rose means the overall impression of the image including all the components or atmosphere that the image creates (79). This allows the expressive content to enhance the meaning of the image by allowing other possibilities.

\section{Institutional Location, Targeted Audiences and Potential Impacts}

In this topic, there is a brief discussion on the institutional location of the images and its impact on the audiences. Since the images are part of the textbooks published by the government institution, targeting the young initial school going audiences, it has potential impacts.

\section{Power/Knowledge Axis in Represented Human Relations}

Power, knowledge and discourse work together as power and knowledge are joined together in discourses (Foucault, The History of Sexuality: Volume I 100). Foucault argued, "Discourse can be instrument and effect of power" (The History of Sexuality: Volume I 101). Foucault claims that knowledge depends on power; by this, he means that power produces knowledge and knowledge further engenders power (Power/Knowledge 52). The power/knowledge chemistry creates and validates the rules and regulations in the society on which the social lives functions (Foucault, Power/Knowledge 131). According to him, power is present everywhere and in all types of relationship. Gender discourse and other social discourses suggested by the textbook cover images and the power/knowledge axis seen in the human relations like gender and other cultural aspects are inspected in this relationship.

\section{Research Methodology}

In this article, the study adopts the qualitative research method. It uses comparative and descriptive techniques while analysing data. It is bounded by a case limited to one educational level (grade one) and one publication (CDC). A comparison between five old and four new textbook cover images of compulsory textbooks was done using a social semiotic approach.

A purposive sampling was used to collect data. As a set of new textbooks were introduced for Grade One in 2019, this grade was intentionally selected for the analysis of textbook cover images for a comparative semiotic analysis across the curriculum. The sample images were used from the Grade One textbook cover images for the study purpose.

The new textbook cover images were obtained from the CDC website, but the hard copies of the old cover images were collected from the CDC office. After the data collection, the cover images were manually coded according to the compositional factors that were significantly different in the old and new textbook cover images. Later, the compositional variations were connoted with the social and semiotic implications.

This study uses Rose's compositional interpretation (56) and discourse analysis (186). The compositional interpretation is used to explore the compositional differences across the curriculum and discourse analysis method is used to explore the implied social 
issues suggested by the image composition. The list of old and new textbooks used in this study is presented in the table below.

\section{Table 1}

List of Garde One Textbooks Covers from the Old Curriculum

\begin{tabular}{ll}
\hline \multicolumn{1}{c}{ Title of Textbooks (Old Curriculum) } & Publication Date \\
\hline My Social Studies and Creative Arts & 2009 \\
My English Book: Grade I & 2003 \\
Mero Nepali: Kakshya 1 & 2006 \\
My Science, Health, and Physical Education: Class 1 & 2010 \\
My Mathematics: Class 1 & 2010 \\
\hline
\end{tabular}

Table 2

List of Garde One Textbooks Covers from the New Curriculum

\begin{tabular}{lc}
\hline \multicolumn{1}{c}{ Title of Textbooks (New Curriculum) } & Publication Date \\
\hline Hamro Serofero: Kalshya 1 & 2019 \\
My English: Book 1 & 2020 \\
Mero Nepali: Kakshya 1 & 2019 \\
Mero Ganit: Kakshya 1 & 2019 \\
\hline
\end{tabular}

\section{Findings and Discussion}

\section{A Semiotic Comparison: The Shift in the New Textbook Cover Images}

There are noticeable shifts in the cover image patterns of the new curriculum. This can be seen in the following images presenting a pair of same subject textbooks belonging to the old and new curriculum. The changes are discussed in detail under the topics given below.

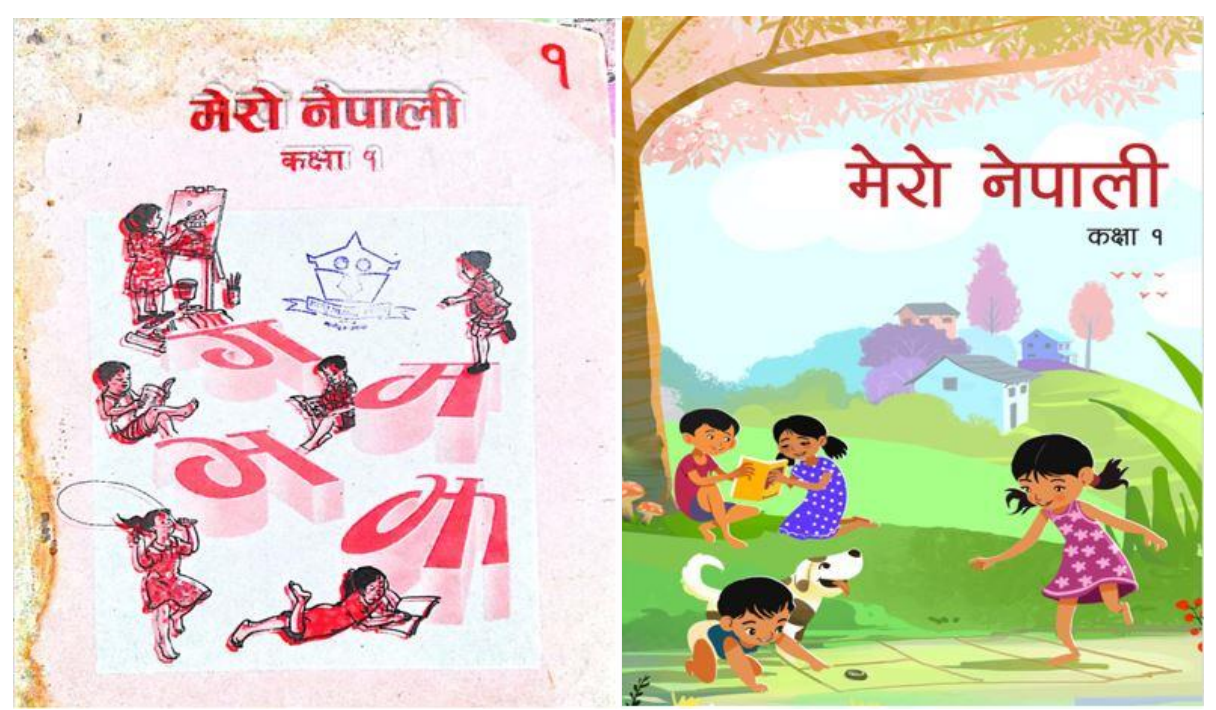

Fig. 1. The old and new textbook cover images from (Mero Nepali: Kakshya Ek, 2019) and (Mero Nepali: Kakshya Ek 2006)

\section{Character and Setting Focused Contents}

The new textbook cover images have focused more on the characters and detailed setting than the old textbook cover images. As seen in the above example, the old textbook cover images have more focused on the activities rather than the characters 
because the characters are relatively smaller and less realistic than the new textbook cover images (see Figure 1). This tendency can be seen in other textbook cover images like My Social Studies and Creative Arts (see Figure 4), My English Book: Grade I (see Figure 2), Mero Ganit: Kakshya 1 (see Figure 5) and My Science, Health, and Physical Education: Class 1 (see Figure 3).

Another significant difference can be seen in the setting. The new textbooks have a detailed setting especially hills featured at the background in of the images. The setting also includes mountains, cattle, typical Nepali houses, greeneries, river, temple and public tap. Especially, the social studies and Nepali language textbooks have focused en more on the detailed setting than the English language and mathematics textbooks. In comparison to the old textbook cover images, the new textbook cover images are more inclusive in the setting.

\section{Focus on the Character Connections}

The connection can be suggested in the images by invisible lines suggested by the direction of characters' looks and gestures (Jewitt and Oyama 141; Kress and Van Leeuwen 42; Rose 66). It can also be implied by the distance between the characters and the shot-distance (Kress and van Leeuwen 124). The nearer the characters are placed the closer their connection is. Similarly, a short distance shot places the characters near to the audiences, establishing a close connection between the characters and audiences. In the new textbook cover images, the character connection is established by putting more than one character near to each other and by their engagement in the same activity. This is maintained in all new textbook covers as all the characters are in pairs in comparison to the images of the old textbook covers where a significant number of characters can be seen playing alone (see Figure 1, Figure 2, Figure 3, Figure 4 and Figure 5).

The character connections are also maintained by the vectors suggested by their eye lines, gestures and their involvement in the same activity. An example can be seen in the following images belonging to English textbooks from the old and new curriculum (see Figure 2). In the new textbook cover image, all the characters are at close distance, involved in the same activity and looking or approaching toward the book showing a strong connection whereas in the old cover image, most characters are engaged in separate activities and they are looking or approaching at various things, suggesting a disconnection.

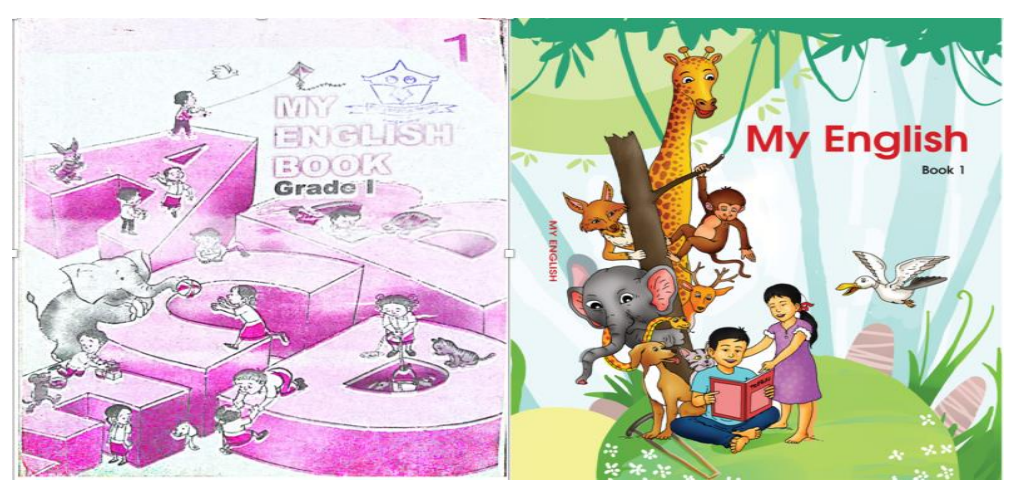

Fig. 2. The old and new textbook cover images from My English Book: Grade I 2003 and My English: Book I 2020.

Another noticeable difference is found in the connection between the audience and the characters. According to Kress and Van Leeuwen, the shot distance places the characters far or near to the audience. The closer shot-distance establishes a connection whereas the farther shot distance suggests disconnections. If the cover images of the new 
textbooks are seen, the characters are nearer and clearer to the audiences than the the old textbook cover images, implying the closer connection to the audiences (see Figure 1, Figure, 2 and Figure 5). The character connection affects the meaning making as the closer connection suggests close relationships among the characters and audiences.

\section{Significant Changes in the Use of Colour}

One of the remarkable changes that is seen in the previous and recent curriculum images is the use of colour. We can see various hues, high saturation, and high value in the latest curriculum making the images more attractive to the eyes. As colour is an important semiotic element that communicates emotions, compose image, and capable of representation it affects the overall meaning making. Colours were one of the important reasons for choosing books by the children and colour preferences were closely linked to the gender (Maniam 162; Yang 674). Children relate and use colour to communicate emotions, represent objects, and to make the image more realistic (Painter 10).

Therefore, use of colours is one of the most significant change that can be seen across the curriculum.

Comparing the previous and current curriculum textbook covers in terms of their colour use, we can see that new cover images have utilised maximum colours to represent objects like houses (red and white colour for the sides and brown for the roof), plants (green trees, bush, and grass), clothing, geography (white mountains, green hills, blue river, green lawns) and characters features (black hair and brown skin). However, previous curriculum textbooks are unable to communicate these details due to limited colour use. Children are expected to like the new curriculum covers than the previous ones however, this is left to further research enquires.

\section{Multiple Picture Image Versus Single Picture Image}

Another important compositional difference is seen in the multiple and single picture composition within the cover image. Three out of five previous textbook cover images present multiple images with various contexts within a single image area (see Figure 1, Figure 3 and Figure 4) however, all the new textbooks present a single image within single setting (see Figure1, Figure 2, Figure 4 and Figure 5). This has resulted in the differences in character connection as multiple pictures in multiple contexts have detached a group of characters from others in previous curriculum textbooks whereas, same settings and similar contexts have bounded characters resembling their close connection in the new textbook cover. As an audience multiple contexts are complicate to grasp as it gives unnatural view to the audience but presents various situations to look at. Whereas single context is easier to understand but deprives us from the dynamics of various contexts.

It can be concluded that the new curriculum textbooks have preferred simple images over multiple pictures and multiple settings within one image. An example of multiple pictures within single image can be seen in the science cover as seen below (see Figure 3). 


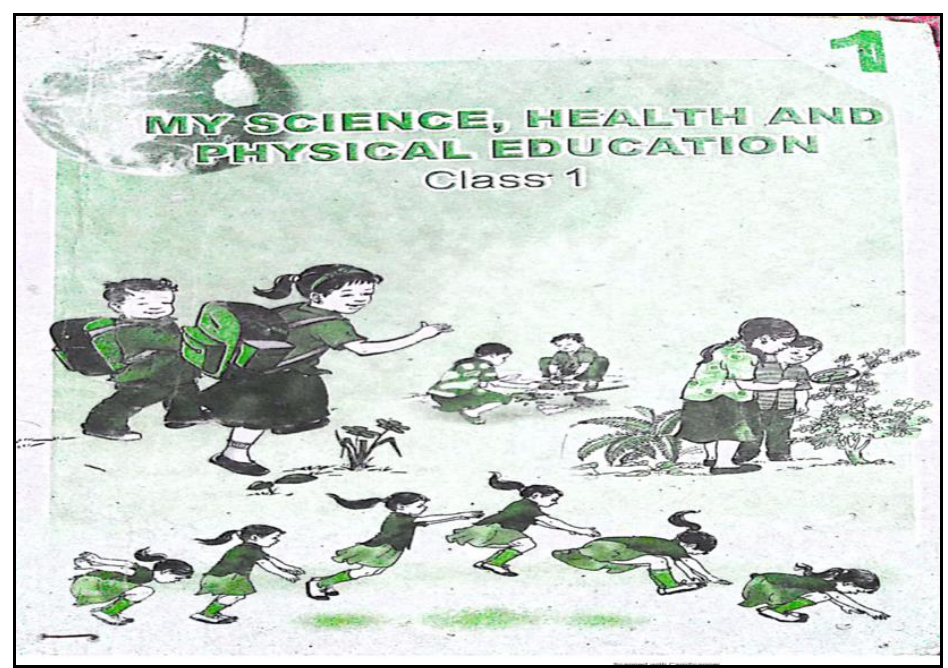

Fig. 3. The old textbook cover from My Science, Health, And Physical Education: Class 1,2010 .

\section{Special Focus on the Young Characters}

Young children are the focused characters in the cover images of both sets of textbooks. Most of the characters are young humans and young animals. Adults are only seen in the social studies textbook covers of both curricula as seen in Figure 4. The new social studies textbook cover shows adult characters at the background and children in the foreground suggesting more emphasis to the children. Likewise, old social studies textbook also displays some teachers and an old man among young children. Except these textbooks, no other textbooks show adult characters. Thus, this can be inferred that the textbook cover images have been inclusive about its audience's age group.

\section{External and Unmediated Point of View}

Another similar feature among the old and new textbook cover images is the presence of external and unmediated point of view. The point of view or focalisation gives a specific viewpoint to the audiences (Bates 276; Painter 32; Rose 71). It can place an audience as somebody looking at the image from a distance without participating in the image world or, can place an audience in the shoe of a character, giving the exact view as the character itself, which is also called an internal point of view. The viewpoints that are not guided are unmediated whereas the mediated viewpoints guide audiences to view the image in a particular way. The internal and mediated point of view makes the audiences more connected with the image world than the external and unmediated point of view.

All the cover images across the curriculum place the audience at a distance giving them external and detached viewpoint (see Figure 1, Figure 2, Figure3, Figure 4 and Figure 5). All the images have unmediated focalisation. This detaches the audiences from the image world and gives them more freedom of focus on the elements presented in the images. The mediated point of view can also be complex for the young children to understand the images.

\section{Representation of Nepali Cultural Context}

The images in the textbook covers reflect the Nepali culture in the image contents. For example, the houses in the cover images of social studies, Nepali language and mathematics resemble the rural thatched roofed houses built with mud and stones 
(see Figure 1, Figure 2 and Figure 5). Especially, the houses as seen in the new social studies cover image represents the colour combination and the architectural aspects of these houses. Similarly, some other cultural features like clothes (sari and blouse in both social studies cover images), greeting gestures (namaste as seen in old social studies book cover), madal (in the old social studies textbook cover), and public tap and temple (as seen in the new social studies textbook cover) (see Figure 4) resemble the Nepali cultural contexts.

The child play activities also give a glimpse of Nepali context. The images showing girls playing Gatta (a game played with five pebbles), kite flying and Dhyakka (a game played with a stone dice) are also relatable to the games played by children (see Figure 1, Figure 2 and Figure 5). Another important feature is the human characters without slippers or shoes (see Figure 1 and Figure 2). This might be unusual to other cultural contexts; however, in Nepal, this is a normal scene mostly in the rural parts where children and even adults are seen without footwear.

From the above context represented in the textbook images, it can be concluded that the textbook cover images resemble the Nepali context and cultural aspects.

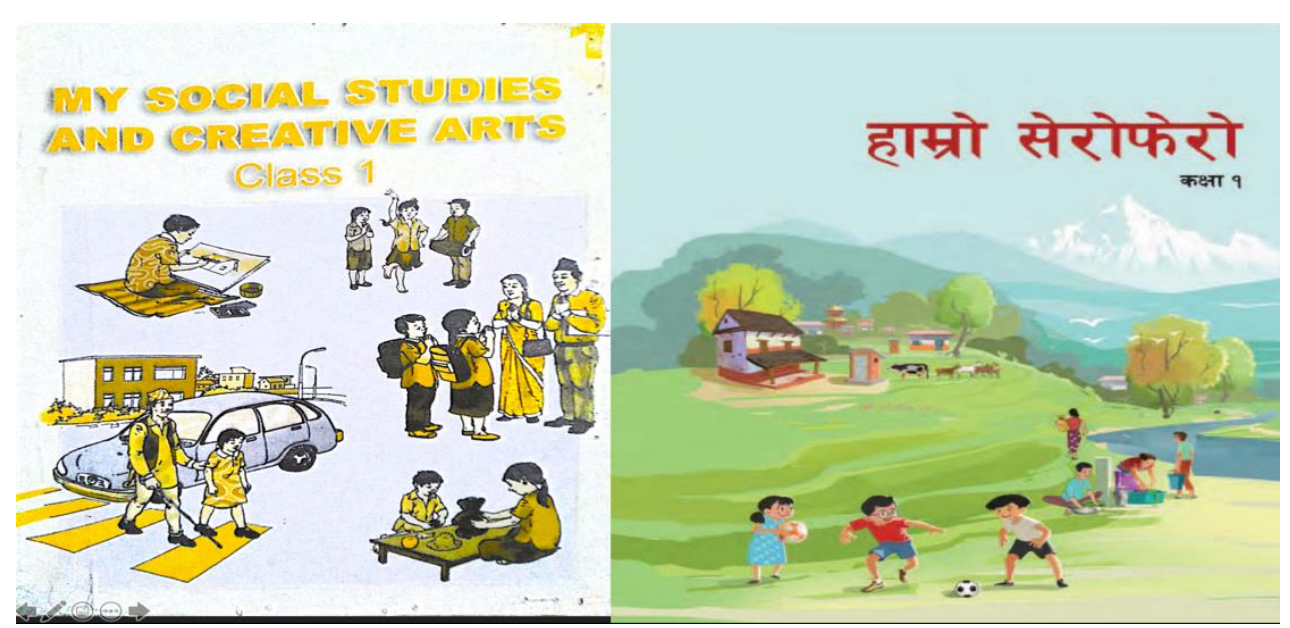

Fig. 4. The old and new textbook cover images from (My Social Studies and Creative Arts: Class I, 2009) and (Hamro Serofero: Kakshya Ek, 2019)

\section{The Presence of Animal and Human Characters}

Another similar feature seen in the old and new textbook cover images is the coexistence of animals and human characters. Three out of five cover images of the old textbooks and three out of four cover images belonging to the new textbooks show the coexistence of animals and humans (see Figure 1, Figure 2, Figure 4 and Figure 5). The new English language textbook cover (Figure 1) and the old English and mathematics textbook covers (Figure 1 and Figure 5) show a close connection between animals and humans as they are participating in the same activities. Among the animals, both wild and domestic animals are seen in the images. All the animals shown in the images are the animals found in Nepal except giraffe in the new English textbook cover.

The presence of animal and human characters suggests the Nepali cultural attitude toward animals. As most of the Nepali follow Hinduism and Buddhism, animals are regarded as the fellow creatures rather than lowly in the hierarchy. Animals like rats, snakes, cows, oxen, dogs, elephants, tiger and so on have a religious significance and are often worshipped during the festivals. Thus, an acknowledgement of coexistence of 
animals in the textbook cover images resembles the Nepali culture based on antianthropocentrism.

\section{Political Aspects of the Images}

The image contents also suggest some political aspects in the way they present the characters, activities and settings. The political power dynamics suggested in the images are important and suggest about what are emphasised upon others. The presence and absence of specific gender, ethnicity, cultural identity and geography in the textbook images published by government publication have a political impact that indicate the national preferences.

\section{Gender Issues in the Images}

The textbook cover images feature some traditionally gender specific activities across the curriculum. For example, playing madal (a Nepali musical instrument), flying kites, playing tyre, etc. are the traditional games for males in Nepal whereas playing gatta (a game played with five pebbles), dance, dhyakka (a game played with stone dice on the floor) are traditionally regarded as female games. The textbook covers also depict male and female specific games in their images (see Figure 1, Figure 2, Figure 4 and Figure 5). This tendency is seen dominant in the old textbook covers than the new textbook covers. Projecting a specific gender in specific play activities in the textbook covers potentially normalise these activities as gender specific activities, impacting the children's gender socialisation.

Some positive changes in terms of children and adult activities can be seen in the new textbook covers (see Figure 4). These changes include both male and female's involvement in household chores and girl child's presence in football with boys. Moreover, no gender division in the indoor or outdoor spaces are maintained across the curriculum. These positive changes can have a positive impact on the children.

The gender segregation in the appearances is maintained across the curriculum (see Figure 1, Figure 2, Figure 3, Figure 4 and Figure 5). Both the old and new textbook cover images present the conventional male/female appearances. In all images, females have long hair and both male and female are wearing gender specific dresses. Gender specific clothes and hair styles reinforce such appearances as normal and limit the individuals to express themselves in alternative ways. It can also be offensive for the non-binary sexual communities and to the people who do not adhere to the conventional gender roles.

\section{Beyond the Gender Issues}

The textbook covers also trigger some political issues beyond the issues of gender that are equally relevant for the social cultural and regional context of Nepal. These issues are discussed in the subsequent paragraphs.

The setting in the old textbook covers have no specific settings that resemble the geographical regions. However, two out of four new textbook cover images (Nepali and social studies textbooks) (see Figure 1 and Figure 4) specify hills and mountains in their setting.

Since new textbook cover images present the characters more clearly than the old ones, the appearances of the adults and children also suggest the people from the hills. Since the mountains have colder climate than the hills and the plains have hotter climate than the hills, they have different types of clothes, facial structures and complexion. The people in the mountains wear thick woollen clothes and belong to Tibeto-Burman ethnicity, having narrow eyes whereas the people of plains have darker 
skin and wear clothes like dhoti (a cotton wrap to cover lower body) and gamchha (a cotton wrap to cover head). These features are neither seen in the images of the old textbook covers nor seen in the new (see Figure 1, Figure2, Figure 3, Figure 4 and Figure $5)$.

Uniquely, Nepal comprises of the hills, mountains and plains that has unique cultures and lifestyles. It is often argued that the nationalist discourse in Nepal is tilted toward hilly nationalism and excludes Madheshis, indigenous, Dalits and women (Lawoti 17). Therefore, depicting only the hilly lifestyle somehow supports this claim of exclusion and shows national endorsement of one culture above others.

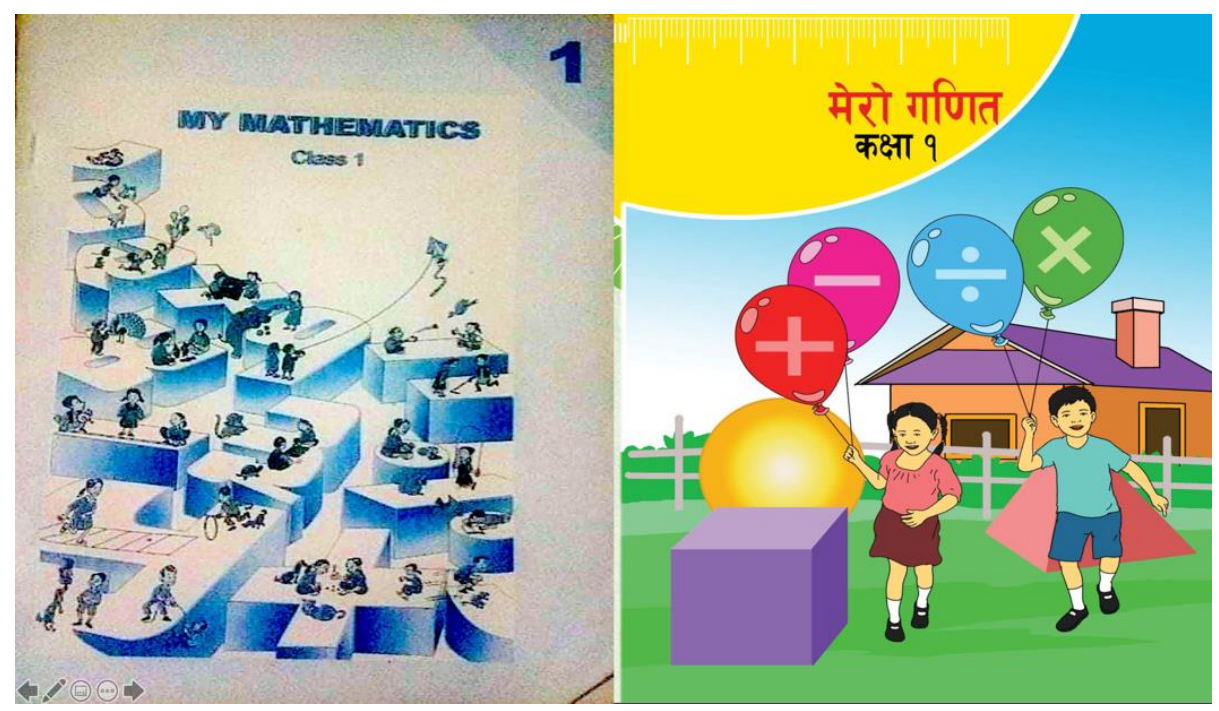

Fig. 4. The old and new textbook covers from (My Social Studies and Creative Arts: Class I, 2009) and (Hamro Serofero: Kakshya Ek 2019)

According to the population census 2011, more than $80 \%$ people belong to Hindu religion (Government of Nepal, 58); however, Buddhism and Islam are respectively second and third highest followed religion according to the same data. In addition, religion is not a static rather a dynamic thing based on personal preferences that keeps changing as preferences change. Being a multireligious and secular country, it is unusual to show religious preferences. However, social studies textbook covers from both curricula show some Hindu religious symbols in the setting and activities (see Figure 4). For example, the new textbook cover shows a temple among the houses in the background in the image. Although there is not any setting in the old textbook cover and has a distant view of the characters, the social studies textbook cover shows women wearing tika and greetings (namaste) as a Hindu symbol. It can be argued that namaste is a national greeting symbol in a formal situation as the context in the given image also represents a formal situation of a meeting between teachers and students. However, since the textbook cover images do not represent any other religious traits, it emphasizes on one culture over the others. Buddhism and Islam have different styles of greeting, as the greetings differ in different cultural contexts.

\section{Conclusion}

This study explored the compositional differences and political discourses prompted by the compositional aspects of textbook cover images, using the old and new textbook cover images of Grade One. According to Sunderland and McGlashan, the textbook covers are the significant unit of analysis because they are the publisher's voice 


\section{Visual Images and Interpretations: A Semiotic Analysis of Textbook Covers 41}

to suggest the overall book contents, 'marketing unit,' and unit of attraction (479). Thus, a comparison between the old and new textbook covers indicates a significant development in quality and other representational aspects.

The findings show that the new textbook cover images have been in many ways different from the old textbooks cover images in the compositional and other qualitative aspects. Having more characters and setting focused the image contents and with colourful textbook covers, the new textbook covers appear more appealing. There is minimal reinforcement of gender specific activities in the new textbook covers. Moreover, the inclusion of counter-stereotypic activities like the girl's presence in the ball game with boys, both male and female adults' presence in the household works, and a balanced gender representation in quantity suggests optimistic changes in the gender based social context. Additionally, a balance in the gender representation in the indooroutdoor setting is also maintained in the new textbook covers, which is a good sign as many studies on the textbook covers claim that there are still issues of male being more in public places and women's presence in private places (Blumberg 350-354). Other findings reveal remarkable changes in the character's details, shot distance, setting details, character relations, etc. There were also similarities in the textbook cover images across the curriculum such as the coexistence of animals and humans, Nepali cultural resemblance, presence of similar external point of view and focus on young characters. Thus, it can be said that remarkable positive changes are seen in the new textbook covers. In this article, the study analyses the cover images of the compulsory school textbooks. Thus, it cannot be generalised that all other textbook cover images also resemble the same thing. The images used inside the textbooks might be different or similar to the images on the textbook covers; thus, this aspect is left for further study.

\section{Works Cited}

Ahour, Touran and Pardis Zaferani. "A Critical Visual Analysis of Gender Representation of ELT Materials from a Multimodal Perspective." Journal of English Language Pedagogy and Practice, vol. 9, no. 18, 2016, pp. 78-98.

Bates, Katherine. "Examination of Images in Australian Standardised Writing Assessments: A Case for Recognising Social and Cultural Disadvantage." Social Semiotics, vol. 28, no. 2, 2018, pp. 257-285.

Blumberg, Rae Lesser. "The Invisible Obstacle to Educational Equality: Gender Bias in Textbooks." Prospects, vol. 38, no. 3, 2008, pp. 345-361.

Callow, Jon. "Classroom Assessment and Picture Books-Strategies for Assessing How Students Interpret Multimodal Texts." The Australian Journal of Language and Literacy, vol. 41, no. 1, 2018, pp. 5-20.

Callow, Jon. "Visual and Verbal Intersections in Picture Books-Multimodal Assessment for Middle Years Students." Language and Education, vol. 34, no. 2, 2020, pp. 115-134.

Crawford, Patricia A. and Daniel D. Hade. "Inside the Picture, Outside the Frame: Semiotics and the Reading of Wordless Picture Books." Journal of Research in Childhood Education, vol. 15, no. 1, 2000, pp. 66-80.

De Lauretis, Teresa. "Gender Symptoms, or, Peeing Like a Man." Social Semiotics, vol. 9, no. 2, 1999, pp. 257-270.

Duncum, Paul. Picture Pedagogy: Visual Culture Concepts to Enhance the Curriculum. Bloomsbury Academic, 2020.

Elmiana, Dewi Satria. "Pedagogical Representation of Visual Images in EFL Textbooks: A Multimodal Perspective." Pedagogy, Culture \& Society, vol. 27, no. 4, 2019, pp. 613-628. 
Visual Images and Interpretations: A Semiotic Analysis of Textbook Covers 42

Foucault, Michel. Power/Knowledge: Selected Interviews and Other Writings 19721977. Translated by Colin Gordon, Leo Marshall, John Mepham and Kate Soper. The Harvester Press, 1980.

Foucault, Michel. The History of Sexuality: An Introduction. Translated by Richard Hurley. Vol. 1, Pantheon, 1978.

Ganea, Patricia A., Megan Bloom Pickard, and Judy S. DeLoache. "Transfer between Picture Books and the Real World by Very Young Children." Journal of Cognition and Development, vol. 9, no. 1, 2008, pp. 46-66.

Good, Jessica J., Julie A. Woodzicka, and Lylan C. Wingfield. "The Effects of Gender Stereotypic and Counter-Stereotypic Textbook Images on Science Performance." The Journal of Social Psychology, vol. 150, no. 2, 2010, pp. 132-141.

Gouvias, Dionysios, and Christos Alexopoulos. "Sexist Stereotypes in the Language Textbooks of the Greek Primary School: A Multidimensional Approach." Gender and Education, vol. 30, no. 5, 2018, pp. 642-662.

Government of Nepal. Hamro Serofero: Kakshya 1. Curriculum Development Centre, 2019.

Government of Nepal. Mero Ganit: Kakshya 1. Curriculum Development Centre, 2019.

Government of Nepal. Mero Nepali: Kakshya 1. Curriculum Development Centre, 2006.

Government of Nepal. Mero Nepali: Kakshya 1. Curriculum Development Centre, 2019.

Government of Nepal. My English Book: Grade I. Curriculum Development Centre, 2003.

Government of Nepal. My English Book: Grade I. Curriculum Development Centre, 2003.

Government of Nepal. My Mathematics: Class 1. Curriculum Development Centre, 2010.

Government of Nepal. My Science, Health, and Physical Education: Class 1. Curriculum Development Centre, 2010.

Government of Nepal. My Social Studies and Creative Arts. Curriculum Development Centre, 2009.

Hamilton, Mykol, et al. "Gender Stereotyping and under-Representation of Female Characters in 200 Popular Children's Picture Books: A Twenty-First Century Update." Sex Roles, vol. 55, no. 11, 2006, pp. 757-765.

Hoel, Trude. "Young Readers' Narratives Based on a Picture Book: Model Readers and Empirical Readers." European Early Childhood Education Research Journal, vol. 23, no. 5, 2015, pp. 673-689.

Hoffman, Angeline P. "A Visual Analysis through the Eyes of an Apache." Critical Content Analysis of Visual Images in Books for Young People: Reading Images, edited by Holly Johnson, Janelle Mathis and Kathy G. Short. Routledge, 2019, pp. 77-94.

Issa, Ola. "'My Grandma Never Lived in Gooligulch': Exploring Gender and National Identity in a Critical Literacy Classroom." Literacy Learning: The Middle Years, vol. 17 , no. 3, 2009, pp. 18-27.

Jewitt, Carey, and Rumiko Oyama. "Visual Meaning: A Social Semiotic Approach." Handbook of Visual Analysis, edited by Van Leeuwen, T., and Carey Jewitt, Sage, 2001, pp. 134-156.

Kim, Hee Young, and Kathy G. Short. "A Picturebook as a Cultural Artifact." Critical Content Analysis of Visual Images in Books for Young People: Reading Images, edited by Holly Johnson, Janelle Mathis and Kathy G. Short. Routledge, 2019, pp. 245-264. 
Visual Images and Interpretations: A Semiotic Analysis of Textbook Covers 43

Kress, Gunther R., and Theo Van Leeuwen. Reading Images: The Grammar of Visual Design. Psychology Press, 2006.

Lawoti, Mahendra. "Informal Institutions and Exclusion in Democratic Nepal." Himalaya, vol. 28, no. 1, 2010, pp. 17-32.

Lester, Jasmine Z. "Homonormativity in Children's Literature: An Intersectional Analysis of Queer-Themed Picture Books." Journal of LGBT Youth, vol. 11, no. 3, 2014, pp. 244-275.

Mallan, Kerry. "Picturing the Male: Representations of Masculinity in Picture Books." Ways of being male: Representing Masculinities in Children's Literature and Film, edited by John Stephens, 2002, pp. 15-37.

Maniam, Mahendran. "What Do Children Look Forward to in a Picture Book?" Language in India, vol. 11, no. 12, 2011, pp. 162-170.

Painter, Clare. "Image Analysis Using Systemic-Functional Semiotics." Critical Content Analysis of Visual Images in Books for Young People: Reading Images, edited by Holly Johnson, Janelle Mathis and K.G. Short. Routledge, 2019, pp. 23-37.

Quinn, Suzanne M. Flannery. "The Depictions of Fathers and Children in Best-Selling Picture Books in the United States: A Hybrid Semiotic Analysis." Fathering, vol. 7, no. 2, 2009, pp. 140-158.

Reyes-Torres, Agustín, and Matilde Portalés Raga. "A Multimodal Approach to Foster the Multiliteracies Pedagogy in the Teaching of EFL through Picturebooks: The Snow Lion." Atlantis, 2020, pp. 94-119.

Rose, Gillian. Visual Methodologies: An Introduction to Researching with Visual Methods. Sage, 2016.

Ryan, Josephine, Anne Scott, and Maureen Walsh. "Pedagogy in the Multimodal Classroom: An Analysis of the Challenges and Opportunities for Teachers." Teachers and Teaching, vol. 16, no. 4, 2010, pp. 477-489.

Schall, Janine M., Julia López-Robertson, and Jeanne G. Fain. "Examining the Visual in Latinx Immigrant Journey Picturebooks." Critical Content Analysis of Visual Images in Books for Young People: Reading Images, edited by Holly Johnson, Janelle Mathis and Kathy G. Short. Routledge, 2019, pp. 59-76.

Sunderland, Jane and Mark McGlashan. "Looking at Picturebook Covers Multimodally: The Case of Two-Mum and Two-Dad Picturebooks." Visual Communication, vol. 12, no. 4, 2013, pp. 473-496.

Sunderland, Jane, et al. "From Bias "in the Text" to "Teacher Talk around the Text": An Exploration of Teacher Discourse and Gendered Foreign Language Textbook Texts." Linguistics and Education, vol. 11, no. 3, 2000, pp. 251-286.

Unsworth, Len and Mary Macken-Horarik. "Interpretive Responses to Images in Picture Books by Primary and Secondary School Students: Exploring Curriculum Expectations of a 'Visual Grammatics'." English in Education, vol. 49, no. 1, 2015, pp. 56-79.

Weitzman, Lenore J., et al. "Sex-Role Socialization in Picture Books for Preschool Children." American Journal of Sociology, vol. 77, no. 6, 1972, pp. 1125-1150.

Yang, Chi Cheung Ruby. "Are Males and Females Still Portrayed Stereotypically? Visual Analyses of Gender in Two Hong Kong Primary English Language Textbook Series." Gender and Education, vol. 28, no. 5, 2016, pp. 674-692.

\section{To cite this article [MLA style]:}

Paneru, Pragya. "Visual Images and Interpretations: A Semiotic Analysis of

Textbook Covers." SCHOLARS: Journal of Arts \& Humanities, vol. 4, no. 1, February 2022, pp. 29-43. NepJOL, doi:10.3126/sjah.v4i1.43051. 